\title{
REASONS FOR PERSISTENTLY HIGH MATERNAL AND PERINATAL MORTALITIES IN ETHIOPIA: PART I-HEALTH SYSTEM FACTORS
}

\author{
Yifru Berhan ${ }^{1}$, Asres Berhan ${ }^{2}$
}

\begin{abstract}
BACKGROUND: Ethiopia is known for its high maternal and perinatal mortalities as in the case of many Sub Saharan African countries probably due to scarcity of health professionals and health facilities. However, there are no reviews that grossly estimated the maternal and perinatal mortality in relation to the number of physicians and hospitals in the country. The purpose of this review is to assess the contribution of health system factors for maternal and perinatal mortalities.

METHODS: A comprehensive literature review was conducted for the period of 1980 to 2012 using the national data for Ethiopia. Data were presented in comparison with the population size, with data from other African countries. Regression analyses of maternal mortality ratio, stillbirth and neonatal mortality rates in relation to number of physicians and hospitals were done.

RESULTS: During the study period, the number of all types of physicians per 10,000 people and number of hospitals per 100,000 people in Ethiopia were in the range of 0.1 to 0.3 and 0.1 to 0.2 , respectively, which were among the lowest in Africa. The regression analyses showed negative correlation of maternal mortality ratio, stillbirth and neonatal mortality rates with number of physicians and hospitals. Ethiopia has already achieved the one health center for 25,000 population plan.

CONCLUSION: In Ethiopia, the physicians and hospitals to population ratios were extremely low, which have probably contributed to the high maternal and perinatal mortality in the last three decades.

KEYWORDS: Ethiopia, hospitals, maternal mortality, physicians, systematic review meta-analysis
\end{abstract}

DOI: http://dx.doi.org/10.4314/ejhs.v24i1.10S

\section{INTRODUCTION}

Like any other health issues, the maternal and perinatal health status of a country is the reflection of the distribution and quality of health services, commitment of professionals and governments, availability of infrastructure, human resource and socioeconomic development $(1,2)$. As a matter of fact, one is likely to be influenced by another and almost all these are some of the developmental milestone indicators of a country. In a little bit extended perspective, the major subdivisions that play direct and indirect roles on maternal and perinatal health include: the utilization and quality of care provided for pregnant women starting from pre-conception, exposure to obstetric and medical complications, the health facilities' infrastructure and set up, the level of education of the woman and her partner, transport availability and access, woman's concern and decision making capacity, cultural and religious influence, and top to bottom health administration scheme and its effectiveness (3-6).

Among others, the purpose of this review is to show how scarce the human and health facility were in Ethiopia particularly for obstetric services. In other words, in this review, we are specifically interested in the number of health facilities

\footnotetext{
${ }^{1}$ Hawassa University, College of Medicine and Health Sciences, Department of Gynecology-Obstetrics

${ }^{2}$ Hawassa University, College of Medicine and Health Sciences, Department of Pharmacology

Corresponding Author: Yifru Berhan, Email: yifrub@yahoo.com
} 
(hospitals and health centers), the number of health professionals (all type of physicians, gynecologists, and midwifes), the number of neonatal intensive care units, the number of blood banks, and selected essential drugs, as a potential contributing factors for the high maternal and perinatal mortality.

In this review, although a definite association of lack of health facilities/human resource with the high maternal and perinatal mortality cannot be shown, the observed gap is a strong evidence to attribute the high maternal and perinatal mortality to lack of health facilities/human resource in the last three decades $(7,8)$. Therefore, the purpose of this review was to show the health professional (particularly physicians) and hospitals gap against the Ethiopian population size and to grossly assess their correlation with the maternal mortality, stillbirth and neonatal mortality rates.

\section{METHODS}

A comprehensive literature review was conducted for the period of 1980-2012. The data sources for this review were electronic databases of MEASURE DHS, World Health Organization, the Ethiopian Central Statistics Agency and the Federal Ministry of Health. One previous study was also used as a secondary data source. The hospitals and physicians number trend were estimated per 10,000 and 100,000 population, respectively. The Ethiopian population size was estimated from the three national censuses (9 11).

Data were presented in line and in bar graphs. The numbers of physicians and hospitals in Ethiopia between 2005 and 2012 were compared with those of other African countries and the other parts of the world by continent. Bivariate Pearson correlation coefficients and regression lines were assessed for maternal mortality ratio, stillbirth and neonatal mortality rates in relation to physicians and hospital number for selected African countries.

\section{RESULTS AND DISCUSSION}

\section{Lack of human resources}

Historically, modern medical practice in Ethiopia dates back to the late $15^{\text {th }}$ century, but organized and institution based medical service was commenced immediately after the battle of Adwa in 1896 (12). However, although modern medical service in Ethiopia is more than a century old, the required number of health professionals has never been met (12). This is in contrary to the population growth. Specifically, in the last 30 years, the Ethiopian population growth was in accelerated phase and may continue with the same rate in the years to come. The population size in 1980 was estimated to be around 32 million, which was about 3-fold less than the current estimate (90 million in 2013).

On the other hand, although the medical school establishment dates back to the 1964, until 2003 , there were only three medical schools with limited enrollment capacity. Up to 2006, there were only 5 medical schools with each enrollment capacity of about 60 students per year. In the health science fields, the pioneering Red Cross Nursing School was established in 1949/50 (just a year after the establishment of the Ethiopian Ministry of Health), the Gondar Public Health College and Training Center in 1954. However, the progress was very slow and unparalleled with the population growth. Until 2006, there were only 88 health sciences training schools (50\% owned by the government) (12).

Regarding maternal and perinatal health, like any other health services, the health team members in the clinical settings are many. It is also known that the good or poor quality of maternal-neonatal health care is the overall effect of the team work. However, we surmise that the role of obstetricians, general practitioners, surgical officers and midwives is superior to other health professionals. In this review, the number of physicians working in the clinical care was given special emphasis. The physician to population ratio may help to estimate the shortage of health professionals and grossly estimate the availability of obstetric care in the available health facilities.

As shown in Figure 1, despite continually increasing population size, the number of all types of physicians per 10,000 population has virtually remained stagnant and has been extremely low over three decades $(0.1$ to 0.2 per 10,000 population). In general, the number of physicians, as one of the indicators of the number of health 
professionals in the public sector in the last 30 years, was extremely low. For instance, the total number of physicians in Ethiopia in 1990 and 2010 was 1596 and 1544, respectively $(12,13)$. The population sizes, however, were estimated to be 48 million and 82 million $(12,13)$. These data show that while the population size doubled in about 20 years' period, the total number of physicians in the public sector remained unchanged. As a result, the physician to population ratios in the 1990 and 2010 were $0.3: 10,000$ people or $1: 30,000$ and $0.2: 10,000$ or $1: 53,000$, respectively.

The magnitude of the problem becomes more severe when the population size is compared with the number of gynecologists. In the first half of 2013, at the national level regardless of working place, there were about 200 gynecologists, making the gynecologist to population ratio about 1: 450,000 (unpublished data). However, the majority of these gynecologists were working either in big towns, in offices (UN agencies and NGOs) or in private clinics and private hospitals. For instance, in the first half of 2013 in the Southern Regional State of Ethiopia, where the population size was estimated to be about 16 million, there were 5 gynecologists working in the public hospitals outside the capital of the regional state, making the gynecologist to population ratio about 1:3.2 million. In Afar, Gambela, Somali and Benshangul-Gumz, the ratio was even lower (1: 5 million) than this ((unpublished data)).

The unfortunate thing is that the gynecologist to population ratio is expected to be even less than the current ratio in the coming 15-20 years unless something is done. This is because, the enrollment capacity of universities for obstetrics and gynecology residency (postgraduate program) is very low and so far there is no green light from the government side to scale up this program.

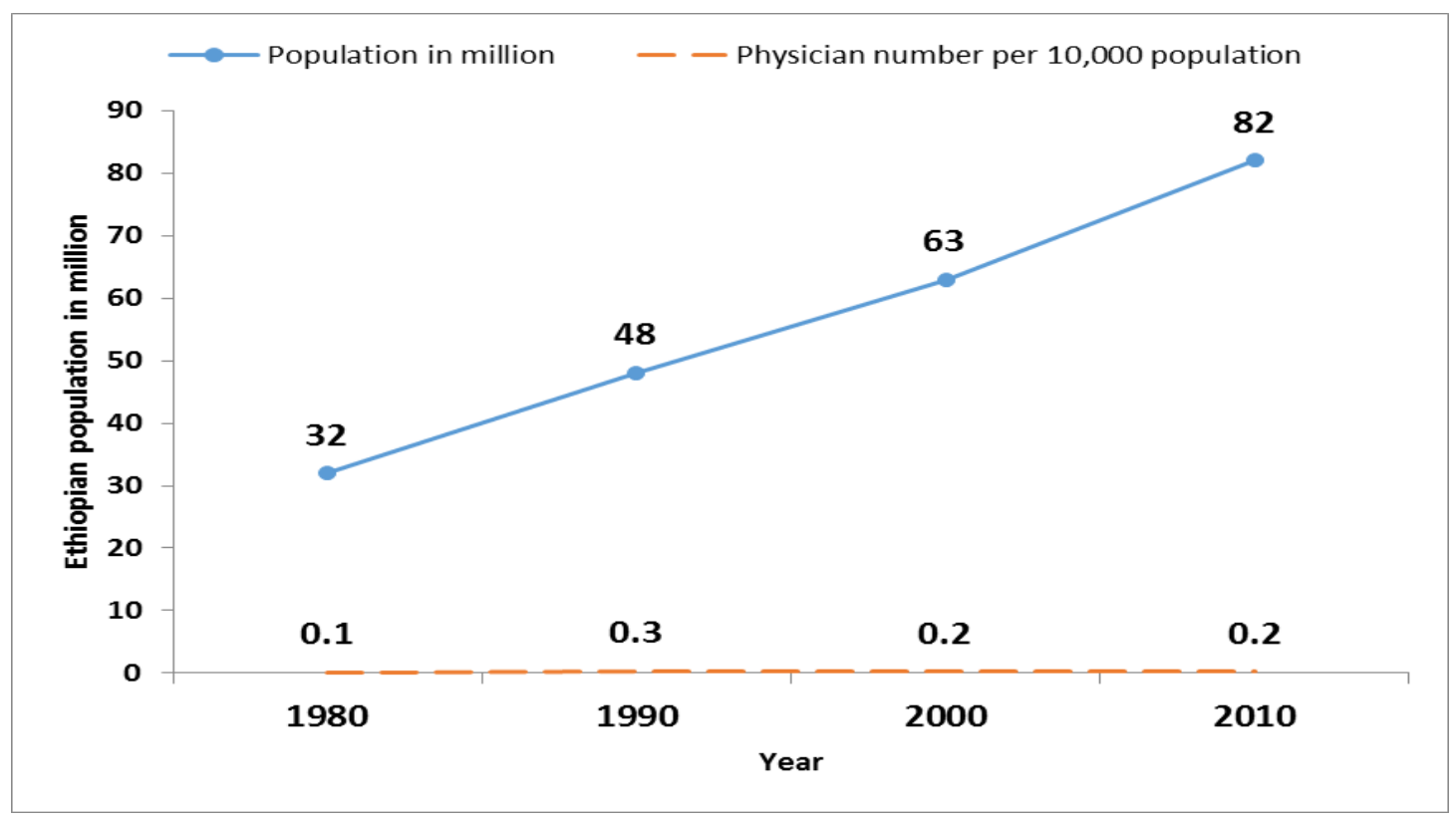

Figure 1: The trend of Ethiopian population in million and number of physicians per 10,000 people, 1980201

Figures 2 and 3 show the extreme shortage of physicians between 2005 and 2010 as compared with some selected Sub Saharan African countries and the developed nations. The mean physician number per 10,000 people for all other African countries was more than 8-fold higher than the Ethiopian figure and 28- and 166-fold lower than South East Asian and European regions, respectively (14). According to the Federal Ministry of Health 2010/2011 report, the lowest ratios were physician to population and midwives to population; there were 938 general practitioners $(1: 87,000), 606$ all types of specialist $(1: 135,000)$, 3702 health officers $(1: 22,000), 2416$ all types of midwives $(1: 34,000)$ and 29,500 all types of nurses (1: 2800) (taking 82 million population size 
estimated for 2010). About five years prior to the 2010/2011 report, the shortage of midwives across the nation was more than the shortage of any other health professionals $(1: 73,000)(13)$.

In general, the number of health professionals (particularly physicians and midwives) in the last three decades was extremely lower than the continuously growing population size. Although there are a myriad of factors, from the health professionals' number perspective, it may not be a surprise why the maternal and perinatal mortality in Ethiopia was among the highest in the world in the previous years.

To achieve the Millennium Development Goals 4 and 5, WHO recommended twenty three doctors, nurses and midwives per 10,000 people to deliver essential maternal and child health services (13). Furthermore, it is said that the availability of skilled health professionals within a supportive health system is the most important factor in keeping women healthy and safe during pregnancy (15).

In Sub-Saharan Africa (SSA), however, the inadequate number and distribution of health professionals is the underlying cause of maternal and perinatal mortality (16), which might also be true in Ethiopia as part of the SSA zone. This is because; the achievement in availing the health workforce in Ethiopia was very far from the recommendation. The disparity even worsens as we go further from the center; the majority of the health workforce concentrated in urban areas. That might have been one of the reasons for the majority of maternal and perinatal deaths that occurred in rural areas (17-20).

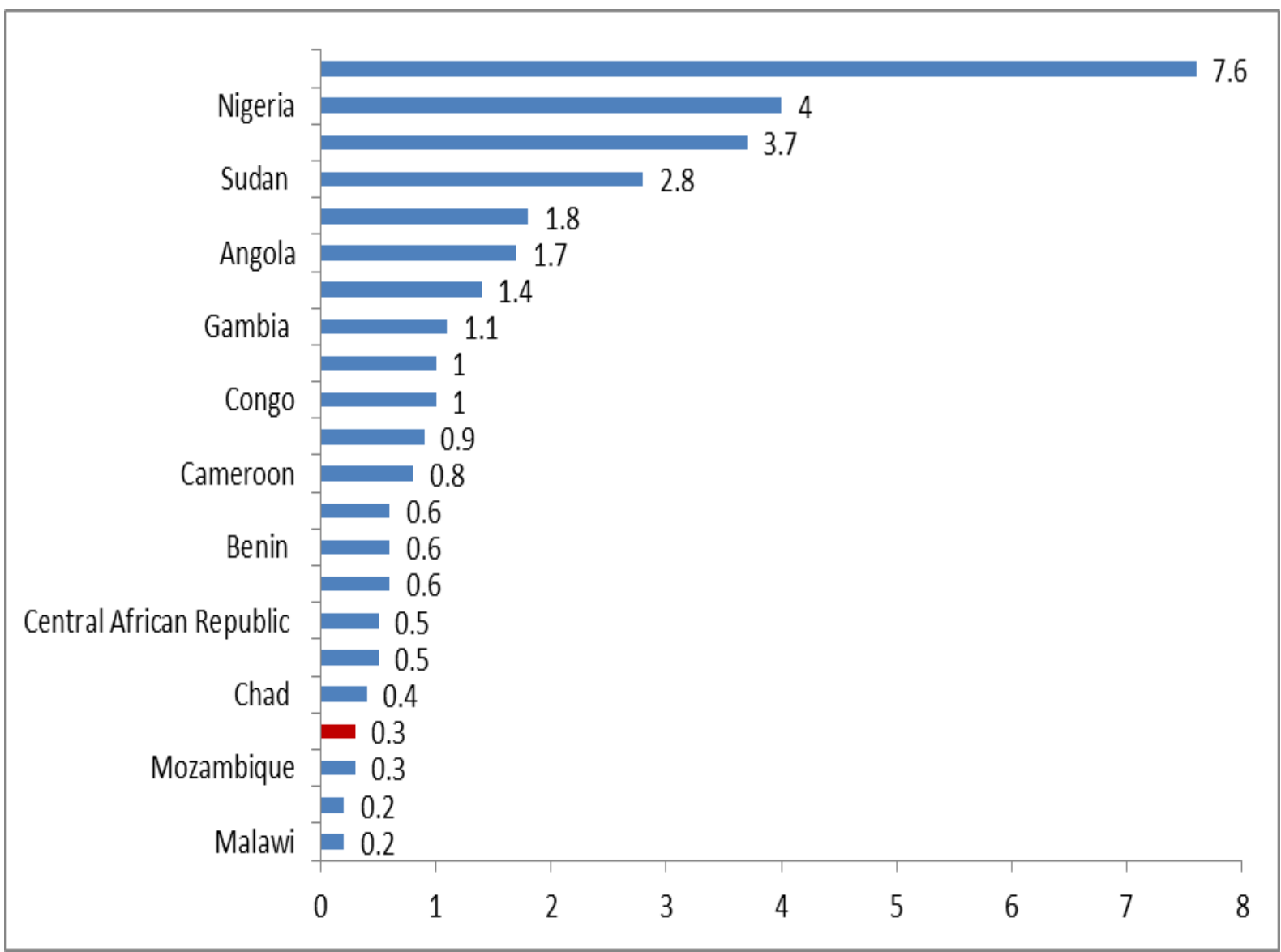

Figure 2: The number of physicians per 10,000 people in Sub Saharan African countries, 2005-2012 


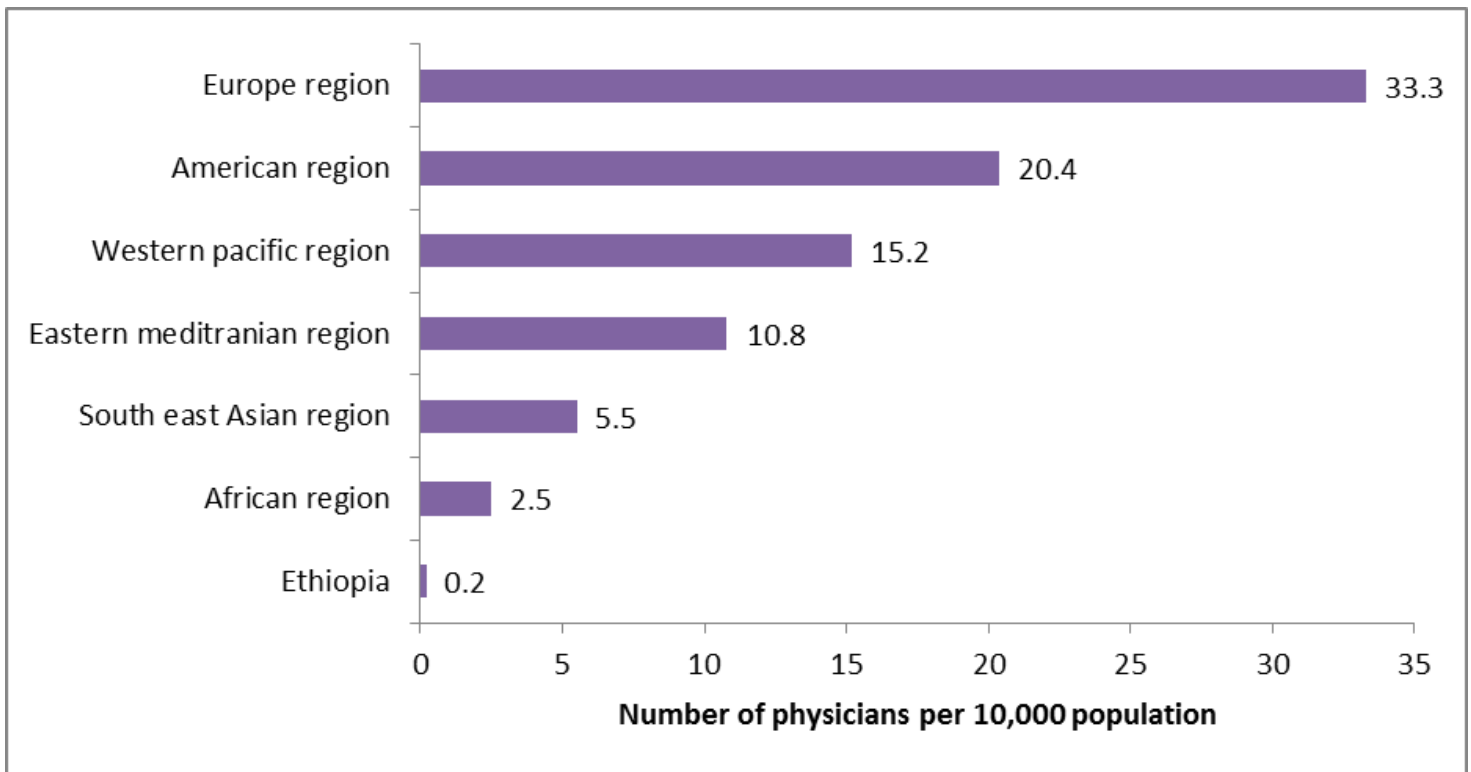

Figure 3: The number of physicians per 10,000 people by region across the world, 2005-2012

As shown in Figure 4, the regression analysis showed that the maternal mortality ratio (MMR) had a negative correlation with the physicians number per 10,000 population $(\mathrm{r}=-0.4 ; \mathrm{P}=0.01)$. The majority of SSA countries with low physician to population ratio had also high MMR. Similarly, the regression line demonstrated the negative correlation of stillbirth rate and neonatal mortality rate with physicians to population ratio $(\mathrm{r}=-0.1 ; \mathrm{P}=0.65$ for stillbirth rate and $\mathrm{r}=-0.5 ; \mathrm{P}=0.01$ for neonatal mortality rate) (Figure 5).
In short, the number of health professionals in Ethiopia in the previous years was incomparably lower than that of several SSA countries. In addition to the massive external and internal brain drain to the greener pasture areas (9), the contributions of the long ago established medical schools were minimal to the demand. As a result, it is the authors' opinion that the extreme shortage of health professionals, in particular physicians and midwives, has contributed much to the high maternal and perinatal mortality in Ethiopia.

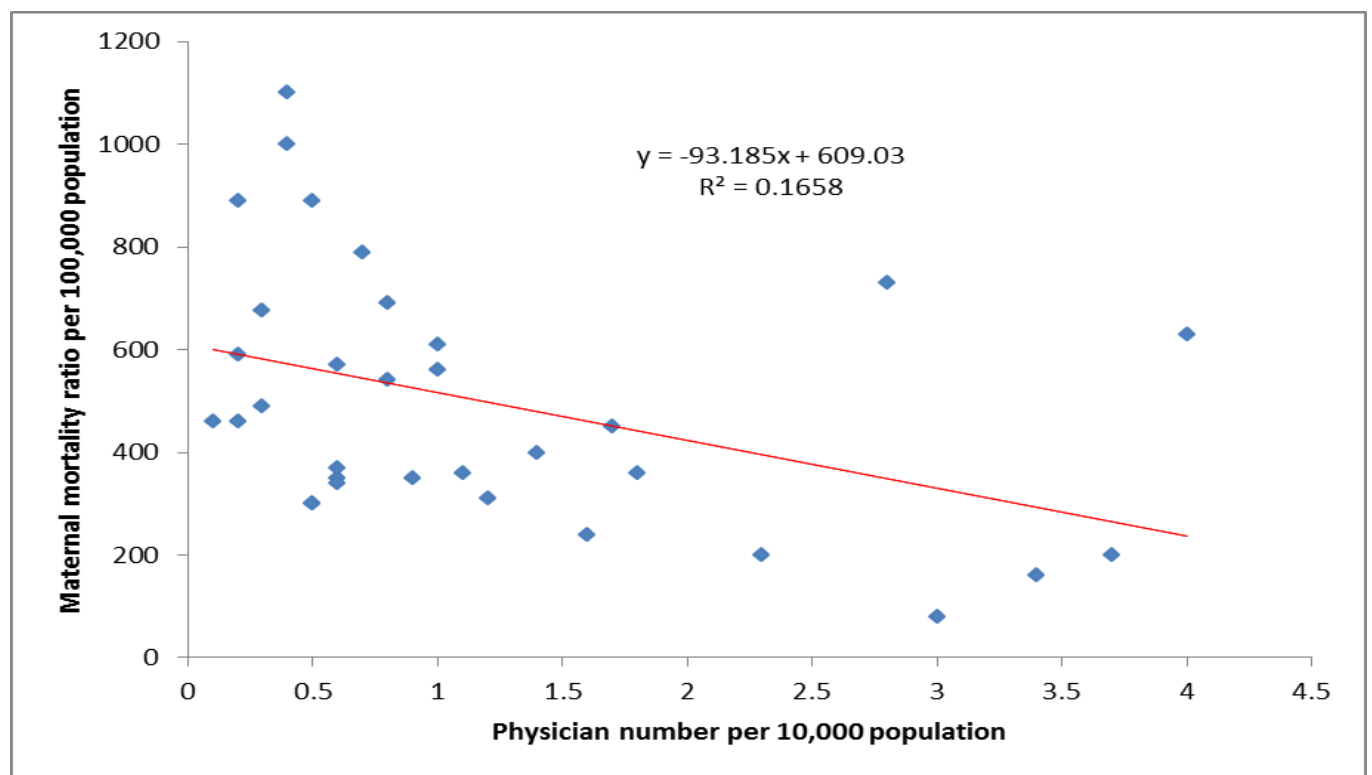

Figure 4: Linear regression analysis of maternal mortality with physicians' number in selected Sub Sharan African countries. Pearson correlation coefficient $(r)=-0.4 ; P=0.01$ 


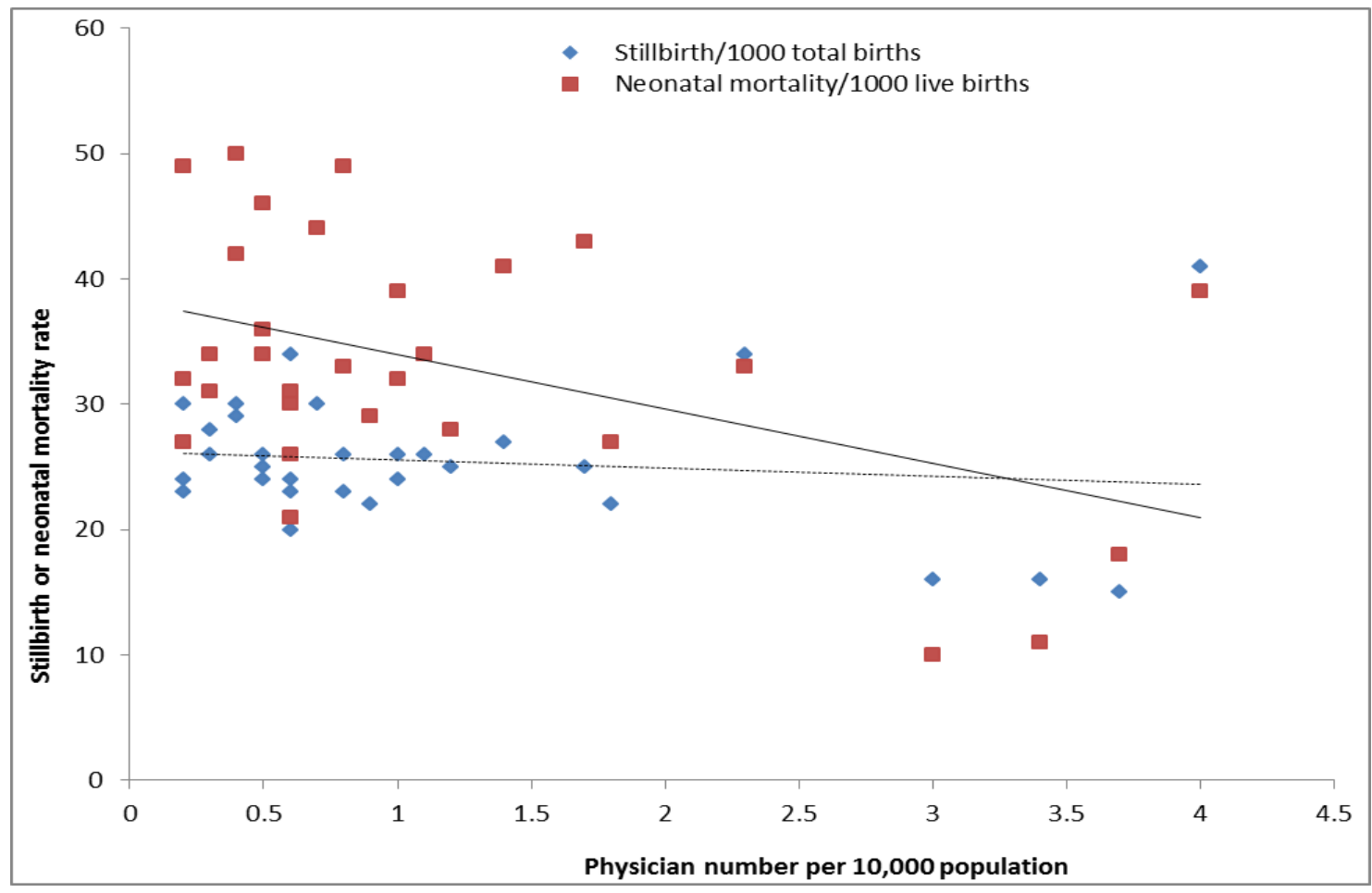

Figure 5: Linear regression analysis of stillbirths and neonatal mortality with physicians' number in selected Sub Sharan African countries, 2009-2011. Pearson correlation coefficient $(r)=-0.1$ and $P=0.65$ for stillbirth rate; $r=-0.5$ and $P=0.01$ for neonatal mortality rate

\section{Lack of access to health facilities}

On the other hand, to make a difference in maternal and perinatal mortality, the importance of establishing accessible, affordable and functioning health facilities is beyond doubt. This is to show whether there were adequate health facilities in reference to the population size in the previous years to provide both preventive and therapeutic health care for the majority.

Specifically, to provide basic emergency obstetric care to prevent and treat the five major causes of maternal mortality (early detection of labor abnormalities to prevent obstructed labor, administration of parenteral antibiotics for sepsis, parenteral anticonvulsants for preeclampsia/eclampsia, parenteral uterotonic drugs and manual removal of placenta to prevent and treat postpartum hemorrhage, and providing abortion care), there should be at least an easily accessible and functioning health center (1 for 25,000 population). Similarly, at least a primary hospital ( 1 for a population of 100,000) should be accessible to the majority to get a comprehensive obstetric care (blood transfusion and cesarean section delivery to prevent morbidity and mortality due to postpartum hemorrhage, obstructed labor and uterine rupture).

In Ethiopia, although the first hospital was established in 1896 (12), the number of the hospitals was not proportionally increasing as the population size increased. In 115 years, only 124 hospitals were constructed (54 in the last 15 years). As shown in Figure 6, the public hospital to population ratio was stagnant (about three hospitals for 100,000 people or 1 hospital in 1 decade). It was noted that the distribution was 0.1 hospital for 100,000 population or 1 hospital for 1 million population. According to WHO estimates (18), the number of hospitals per 100, 000 people (including private hospitals) for the years 20052010 was 0.2, which was among the lowest in Africa (Figure 7). 


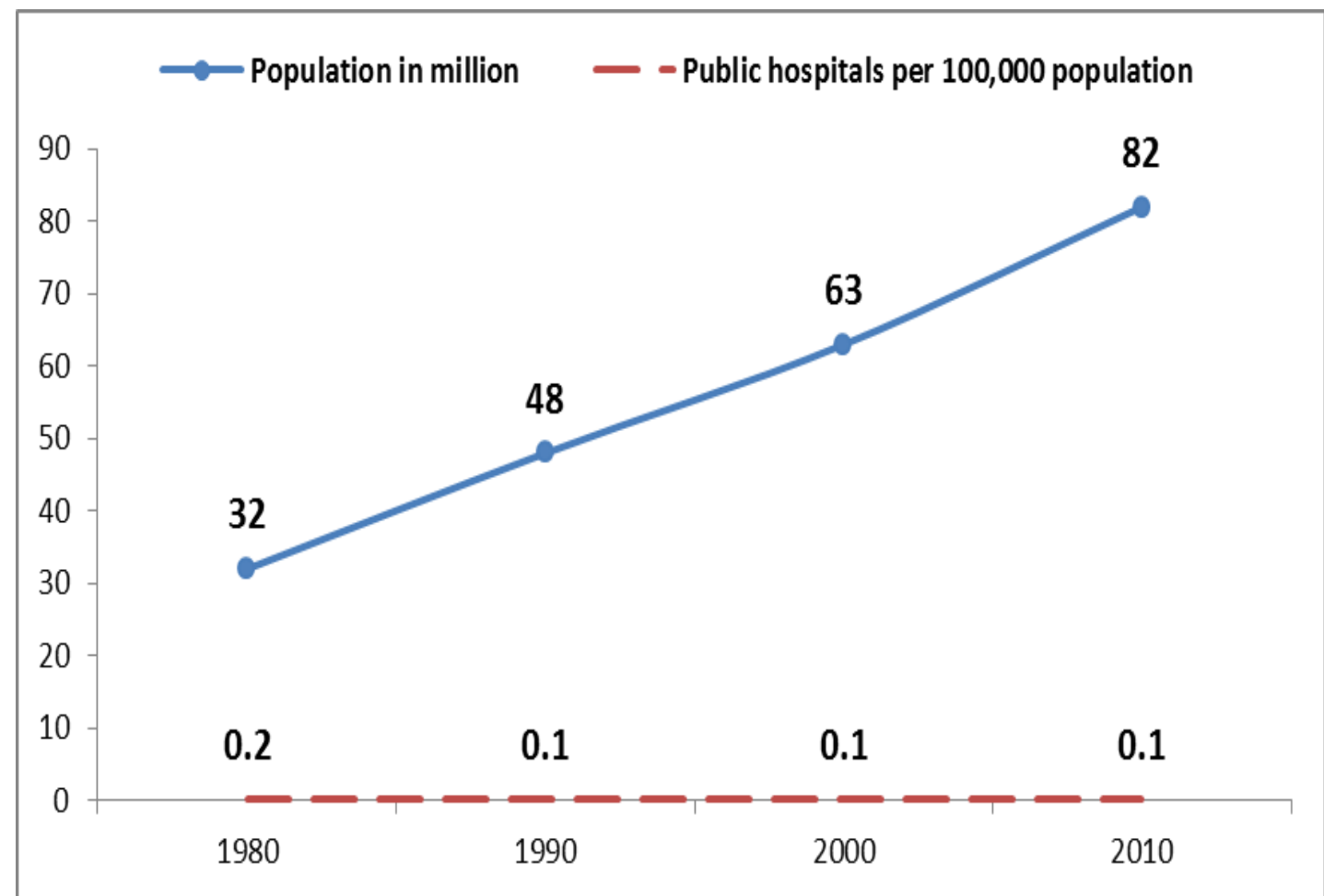

Figure 6: The trend of Ethiopian population in million and number of hospitals per 100,000 people, 1980 2010

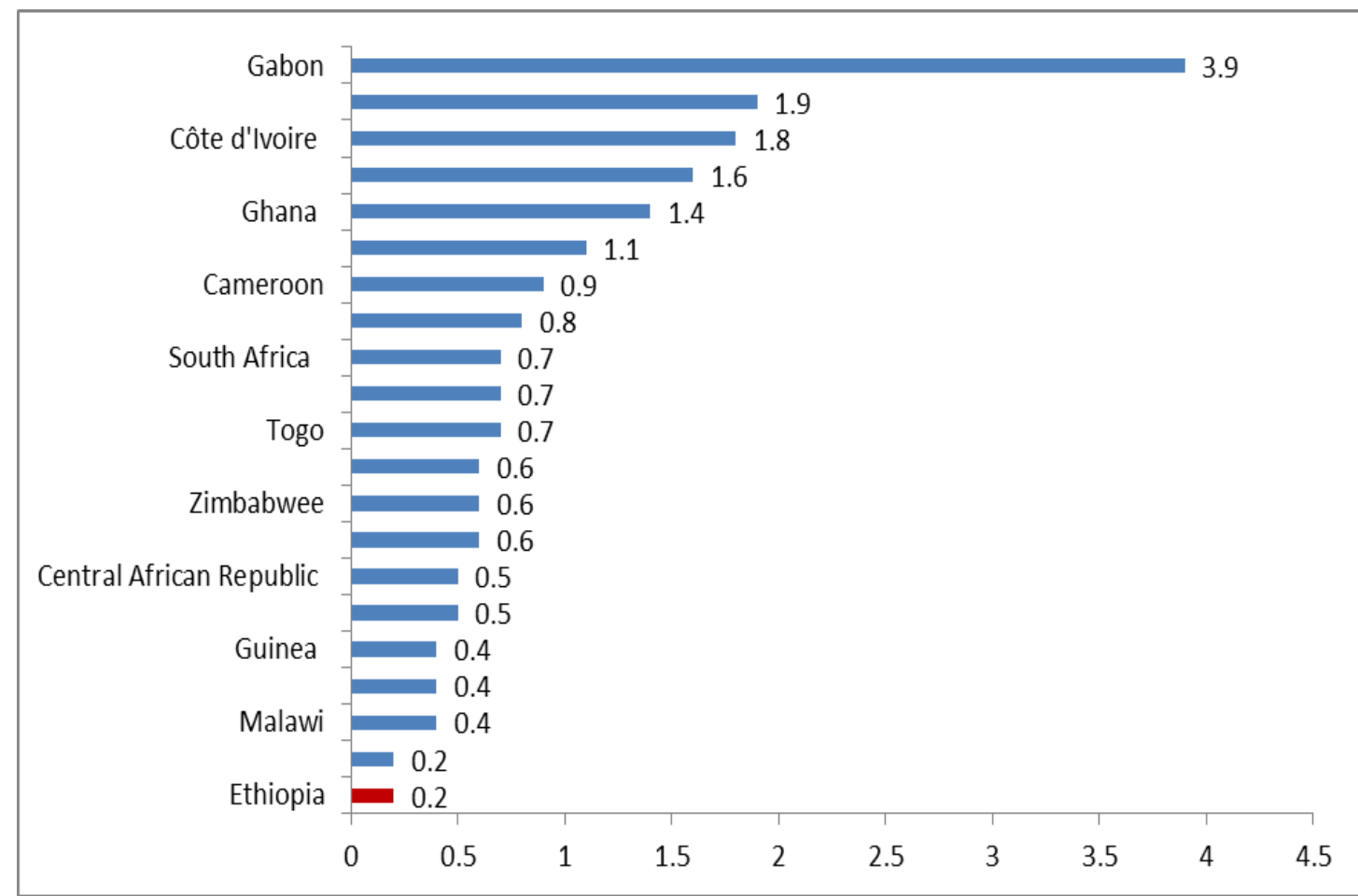

Figure 7: WHO estimates of the number of hospitals per 100,000 people for the year 2005-2012 for Sub Saharan African countries, 2005-2012 The 2010/2011 
The Federal Ministry of Health report was consistent with the WHO estimation (total 178 hospitals for 82 million people, which was equivalent to 0.2 hospitals per 100,000 people) (13). The number of health centers, however, increased from 279 in 1998 to about 2660 in 2010/2011, which was more than 12-fold increment in about a decade $(12,13)$. From unpublished data source (Federal Ministry of
Health), the number of health centers increased to more than 3500 by the year 2013 (Figure 8). As a result, the recommended health center to population ratio $(1: 25,000)$ has been already achieved. However, we do not know how many of these health centers are fully equipped with material and human resource, and ready to provide emergency obstetric care.

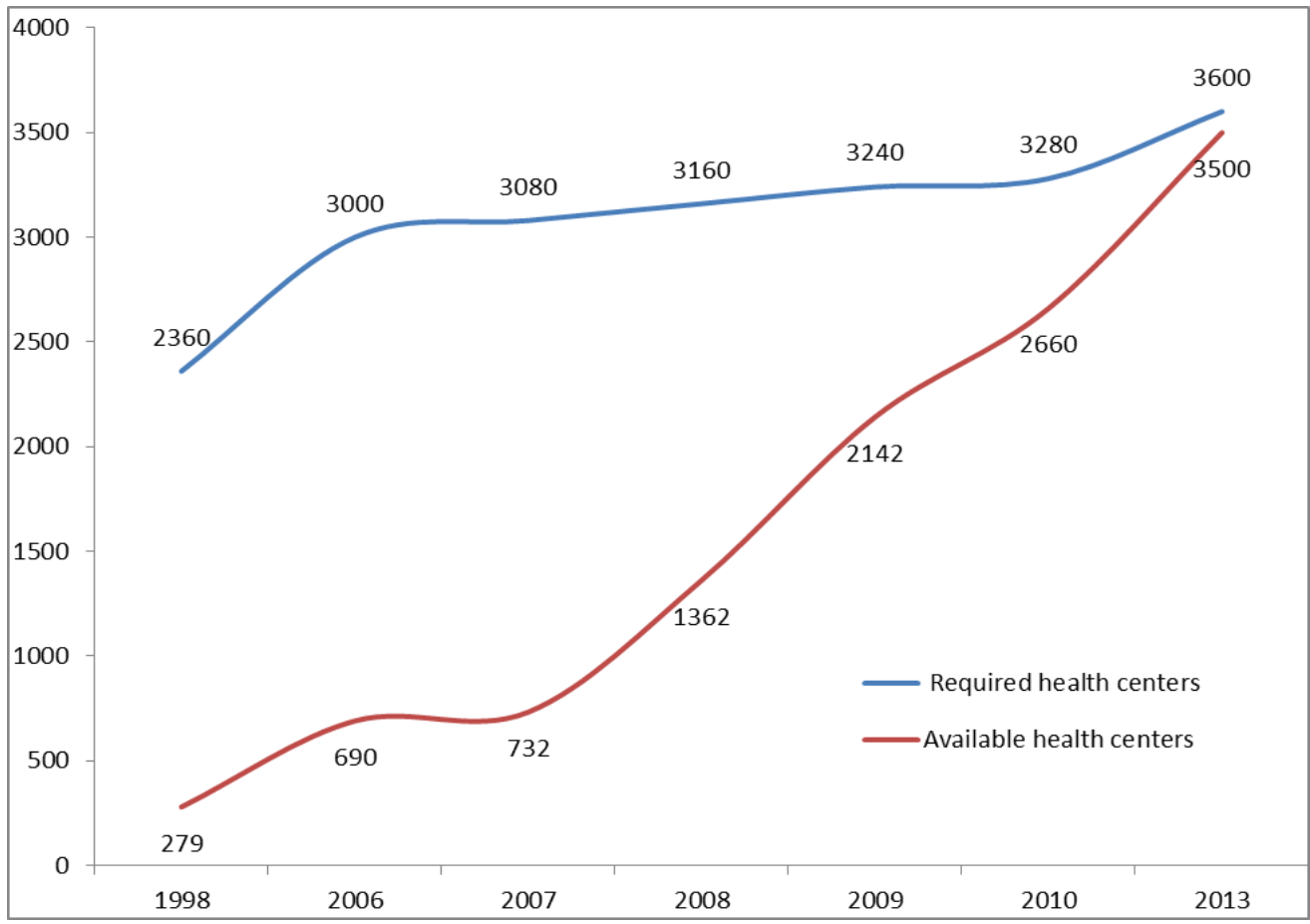

Figure 8: The number of available and required health centers per 25, 000 people in Ethiopia, 1998-2013. The reference was the population size and the recommended health centers (1 health center for 25, 000 people)

Since the interest of this review is performances of the past, the shortage of both hospitals and health centers was very remarkable and incomparably lower than that of almost all of the other SSA countries. We surmise that the extreme shortage of health facilities and health professionals, particularly for the rural population, is a principal cause for the high maternal and perinatal mortality in the previous years.

Probably, as supporting evidence for the contribution of shortage of hospitals to maternal and perinatal mortality, SSA countries with lower hospital to population ratio were found to have higher MMR ( $\mathrm{r}=-0.4 ; \mathrm{P}=0.02)$ (Figure 9). The regression line for stillbirth and neonatal mortality rates in relation to hospital to population ratio in selected SSA countries also showed a weak negative correlation (Figure 10). Except in Cote D'Ivoire, despite the relatively high hospital to population ratio, the MMR and stillbirth rate was high. 


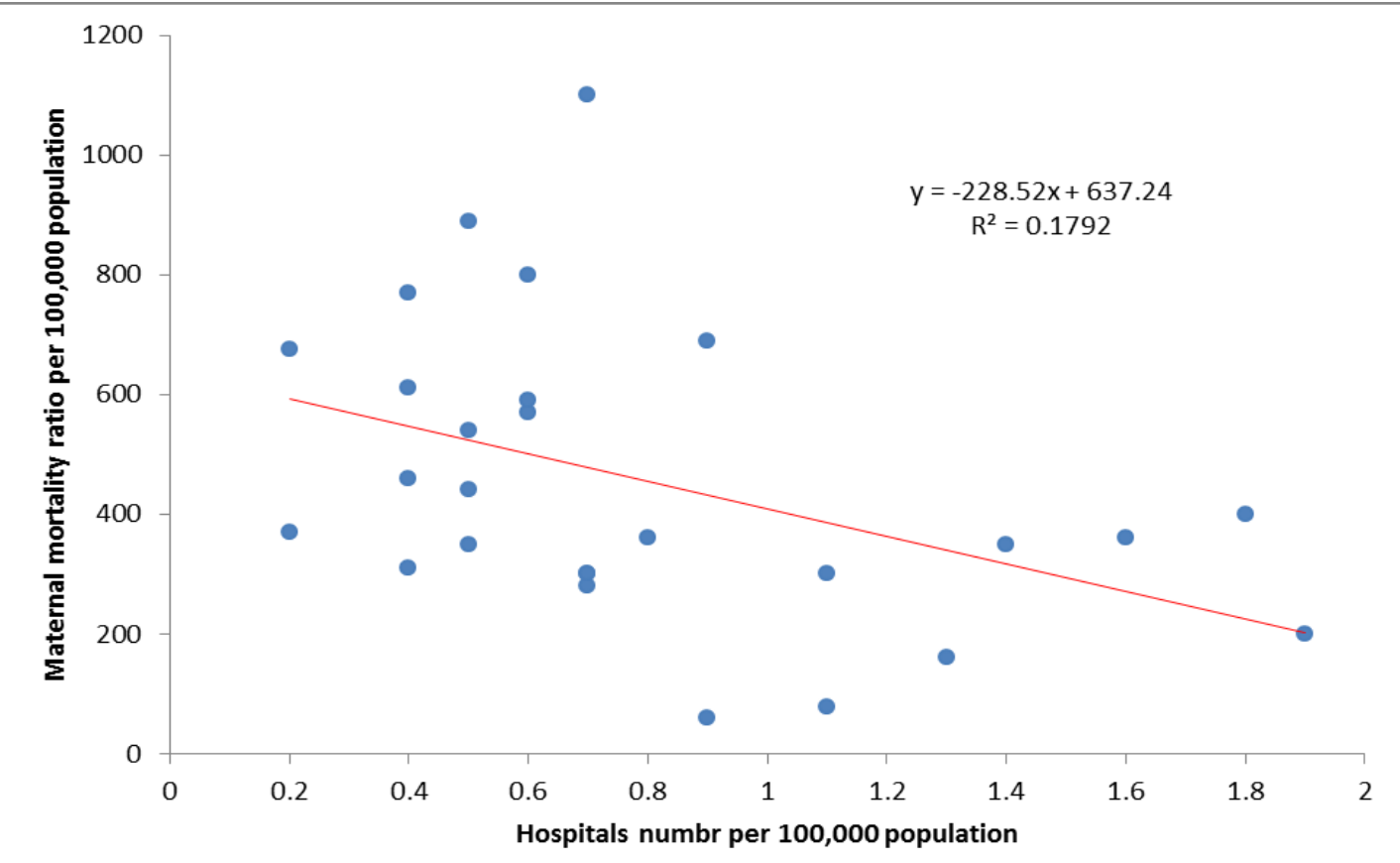

Figure 9: Linear regression analysis of maternal mortality ration with hospitals number per 100,000 people in selected Sub Sharan African countries, 2009-2011. Pearson correlation coefficient $(r)=-0.4 ; P=0.02$

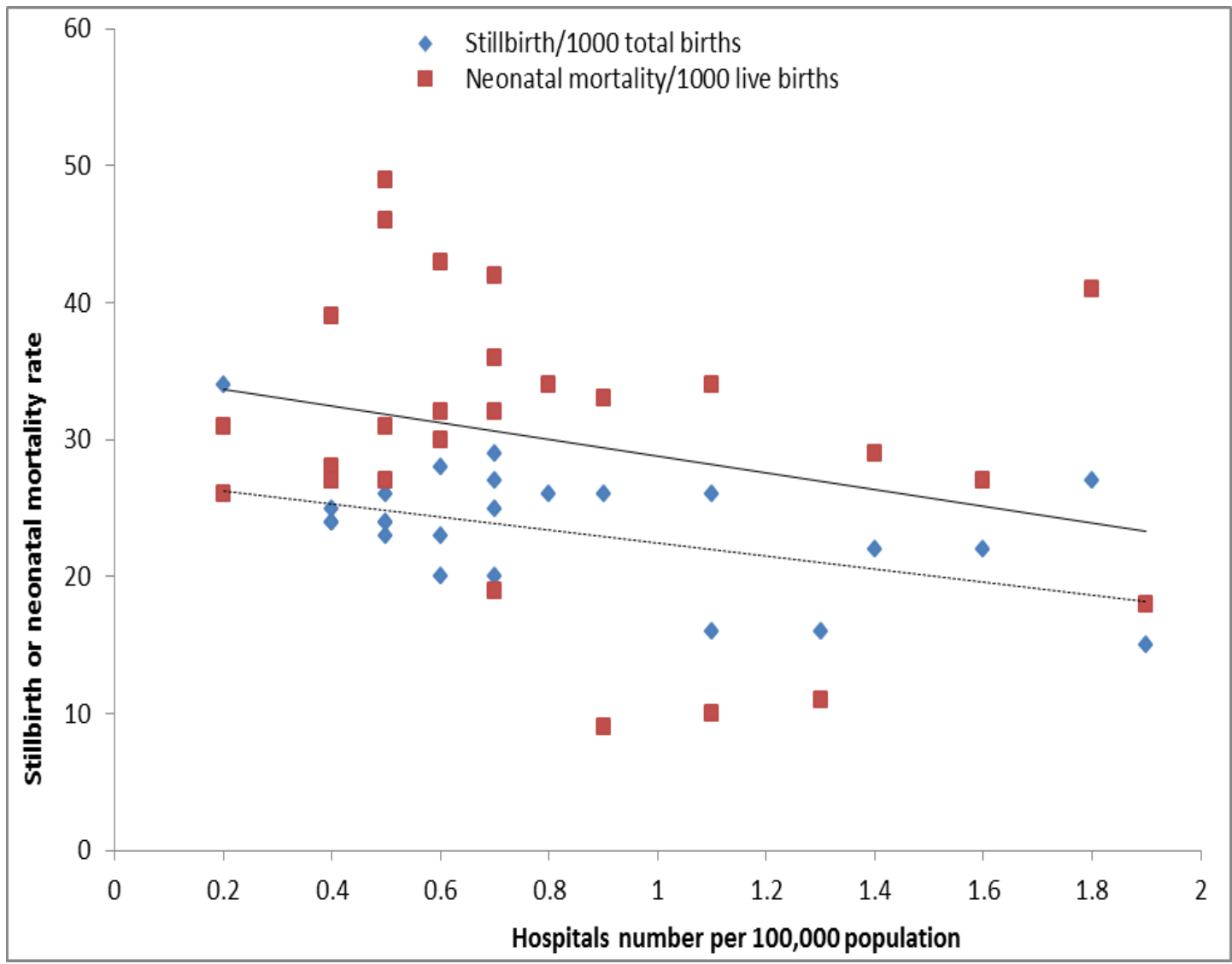

Figure 10: Linear regression analysis of stillbirths and neonatal mortality rates with hospitals number in selected Sub Saharan African countries, 2009-2011. Pearson correlation coefficient $(r)=-0.4$ and $P=0.02$ for stillbirth rate; $r=$ - 0.3 and $P=0.2$ for neonatal mortality rate 
Detail discussion regarding common causes of maternal and perinatal mortality is found elsewhere $(8,21)$. The review revealed that mechanical causes (obstructed labor and uterine rupture) were the leading causes of maternal and perinatal mortality. As the middle to high income countries experiences showed, had there been health facilities providing comprehensive emergency obstetric care close to the majority/rural women, there could not have been such high maternal and perinatal mortality in Ethiopia.

\section{Lack of blood banks}

Obstetric hemorrhage is among the top three causes of maternal mortality and morbidity. Specifically, antepartum hemorrhage is one of the common causes of perinatal mortality, mainly due to prematurity and severe anemia (22-24). Avoiding the occurrence of all types of obstetric hemorrhage is impossible but replacing the lost blood with blood or substitutes is a routine practice in modern medicine. In Ethiopia, because of big delays before or after the onset of bleeding, management of obstetric hemorrhage is: 1) very challenging and resource intensive, 2) usually associated with high maternal and perinatal mortality and morbidity, and 3) suboptimal (24).

A 7-year cohort study in Hawassa University Hospital revealed that the proportion of overall severe anemia increased from about $28 \%$ on admission to $41 \%$ at discharge (23), which showed inadequate blood transfusion due to inadequate blood in the bank. Unlike reports from other countries, in this study there were $50 \%$ perinatal deaths (38\% stillbirth).

This is a good example of how fatal obstetric hemorrhage problems are and how severely compromised the obstetric management is due to the delay in Even after arrival. It has shown how challenging blood transfusion is due to incapacitated blood transfusion setting in the hospital. In other words, if the central referral and a university hospital in the Southern Region is as such incapacitated, it is easy to imagine the situation in the district and zonal hospitals. One WHO review has shown that maternal mortality in SSA due to hemorrhage (34\%) was incomparably higher than other causes (25).

Another systematic review also showed that 20 of 37 selected studies demonstrated a direct association of maternal deaths with lack of blood transfusions in SSA. In this review, nonaffordability of blood, lack of blood donors, the unwillingness of relatives to donate blood and inadequate supplies and transport were the major reasons for lack of emergency blood transfusions. Recommended solutions were more blood donations, better financing mechanisms and efficient management systems (26). These recommendations are true in a place where the blood bank is established. In Ethiopia, however, the majority of the hospitals are not yet backed up with standard blood banks.

The Ethiopian Red Cross Society National Blood Bank Services (ERCS-NBBS) was established in 1962 . This society has been the only organization in the country authorized to collect and distribute blood (27). The central blood bank was established in the capital and has been the one fully functioning blood bank to supply blood and blood products to hospitals in the capital city. There are eleven regional blood banks established in Yirgalem, Arbaminch, Adama, Harar, Diredawa, Jigjiga, Mekele, Gondar, Bahirdar, Dessie, and Jimma. Unfortunately, all the regional blood banks have very limited capacities-not beyond collecting and distributing blood only to a single hospital. As a result, it was very difficult to say that they had been functioning as blood banks for hospitals in their catchment areas. In more than 50 years of service, the only blood bank which was functioning as its name implies was the central blood bank.

This happened although the country's blood demand is estimated to be above 100,000 units per year. The Ethiopian Red Cross Society has constructed 16 additional blood banks and has initially got the mandate to implement the five year safe blood strategy of the FMOH to give blood service access to hospitals across the country (2009-2013). Recently, however, the Ethiopian Red Cross Society has handed over all the blood bank service to the FMOH probably for a good reason (27).

In Ethiopia as well, the issue of blood transfusion goes beyond establishing the blood bank. It is known that although there are no blood banks around the majority of the hospitals outside Addis, several hospitals have organized a mini blood bank in their laboratory rooms, or blood donation and transfusion may be possible on 
demand base. The big challenge commonly encountered by clinicians usually in public hospitals with no access to blood bank is the lack of important supplies and lack of voluntary blood donors. Blood is usually collected from incidental donors (usually a family member). However, because of low awareness, many family members are not volunteering to donate blood to their family members even on the verge of their relative's death. This is a common melancholy for public hospital staff.

Family members usually prefer to find somebody who can donate blood for fee. As a result, it is not uncommon for family members to pay more for a blood seller than the actual health service fee. These days, it is becoming a business for some guys in the urban areas (one unit blood costing up to 80-100 USD) at unaffordable cost for patients and relatives. Beyond the cost and lack of donors, to our knowledge, there is no law that allows or prohibits selling blood.

Had there been a blood bank near to the hospitals and donating blood for free was advocated using mass media or other forum, the needy people would not have suffered from double trauma (the blood loss and the cash loss). In short, another review in this analysis has shown that maternal mortality due to hemorrhage was in increasing trend in the last three decades (21). Therefore, to make a difference in maternal and perinatal health, establishing blood banks to at least in the zonal level has to be the Government's and other stakeholders' priority.

\section{Lack of magnesium sulphate}

Among several essential drugs for maternal and perinatal health, magnesium sulphate is the interest of this review. To be more specific, preeclmpsia/eclampsia is among the top three causes of maternal mortality and morbidity. Another review has revealed that maternal mortality due to hypertensive disorders of pregnancy is in increasing trend in the last decade (21). Hypertensive disorders of pregnancy are also among the leading causes of perinatal mortality and morbidity (8). Therefore, as a strategy to reduce maternal and perinatal mortality, preventing or treating these two maternal life threatening obstetric complications is a priority.

In Ethiopia, however, for several decades the anticonvulsant drug used for women with hypertensive disorders of pregnancy was diazepam. Because of its adverse effects, and above all, because of its poor efficacy in preventing convulsion, the maternal and perinatal complications and deaths were very high. It is the authors' assumption and observation that the poor efficacy of diazepam has contributed its share to the high maternal and perinatal mortality and morbidity.

Magnesium sulphate as anticonvulsant for hypertensive disorders of pregnancy was initially used widely in the 1990s in the United States of America. Later on, in almost all developed nations, it became the first drug of choice for preventing convulsion during pregnancy. Its popularity has increased not only because of its high efficacy in preventing convulsions and improving maternal and fetal survival but also because of its fewer side effects to the fetus and the mother (28-30).

In Ethiopia, Magnesium sulphate is included in the essential drugs list. However, the distribution has been limited to public hospitals and few health centers. In Hawassa University Hospital, there has been a continuous supply of this drug in the last two years, and more than 600 hypertensive pregnant women were treated. It was observed that the maternal and perinatal outcomes of women with hypertensive disorders have significantly improved (unpublished data from 6 years cohort study).

During the era of diazepam, pregnant women with hypertension were experiencing several episodes of convulsion even after the diazepam drip was initiated. To the contrary, in the last two years, we encountered convulsions very rarely with the introduction of Magnesium sulphate. With the existing system, the authors noticed that professionals working in health centers and district hospitals were not properly trained, and the antidote (calcium gluconate) was found very rarely even in big hospitals.

The unavailability of Magnesium sulphate prior to two years in all hospitals might have contributed to the high maternal and perinatal mortality due to hypertensive diseases in the last three decades. Therefore, the supply (both magnesium sulphate and calcium gluconate) and in-service training of the professionals on how to use these medications have to be areas of concern 
to reduce the maternal and perinatal mortality and morbidity in the years to come.

\section{Lack of neonatal intensive care units (NICU) and newborn corners}

According to the UNICEF 2009 report (31), every year more than 120,000 children die during the first month of life in Ethiopia; of these deaths, asphyxia alone contributes to more than $23 \%$. The argument is that a significant proportion of asphyxia related mortalities can be prevented by having a neonatal intensive care unit (NICU) or newborn corners with basic equipment and trained health personnel.

For more than half a century, however, the only hospital that has established NICU in Ethiopia was only one TikurAnbessa Hospital in the capital. This unit (poorly equipped) has been functioning as a neonatal admission unit mainly for neonates delivered in the same hospital and occasionally for neonates referred from hospitals and health centers in the capital. With the support of the International Fund for Africa, two more NICUs (at Yekatit 12 and Ghandi Memorial Hospitals) were established in Addis in the last five years.

It should also be noted that 4 university hospitals outside the capital (Mekele, Gondar, Hawassa and Jimma) have also established NICUs. However, their capacity to provide intensive neonatal care is very limited because of lack of essential medical equipment and neonatologist. There are also few public hospitals which have recently established NICUs (Debreberhan, Bishoftu and probably some more). But, the majority of the public hospitals have not yet established NICU.

Taking this big gap into account, the Ethiopian Federal Ministry of Health (FMOH) in collaboration with UNICEF and WHO has launched a Newborn Corner Initiative in 2009 that aims to curb the tragic situation with regard to neonatal health. The newborn corners were planned to be established in the health centers across the country. As a result, it was envisaged that this initiative will address gaps in preventing newborn morbidity and mortality in the country thereby ensuring standard newborn care immediately after birth in health facilities. So far, the progress in all regional states was reported as going well in terms of availing the minimum required equipment and supplies to make the newborn corners functional. The authors had a chance to visit several health centers in the Southern Region where he observed that the equipment is in place but the professionals working in the health centers were not trained on how to operate and utilize them.

It should also be noted that establishing newborn care requires very expensive equipment, trained health personnel and well illuminated and warm rooms. To fill the gap, the Ethiopian pediatrics society is collaborating with the FMOH in establishing NICUs and newborn corners and providing training for health professionals. This society commenced supportive supervision for 800 health centers starting from December 2012 and so far more than 1000 professionals were trained at the national level.

The problem with neonatal care in Ethiopia goes beyond a shortage of trained health professionals, NICU or newborn corner in the available health facilities. To begin with, despite high neonatal mortality in the country, it is very unusual to find sick neonates coming to health facilities from home probably because of lack of awareness or lack of functioning health facilities or absence of advocacy on neonatal health service. Secondly, very few universities are graduating generalists in pediatrics. Therefore, in addition to establishing newborn corners and NICU in public health facilities, a postgraduate program (Neonatology or Perinatology) should be launched at least in some of the old medical schools. Furthermore, in-service trainings on newborn resuscitation, BEmOC and CEmOC should run in parallel with the establishment of NICUs.

This review has limitations. Because of variations in the distribution of health professionals and facilities, the national estimation of maternal and perinatal mortalities may not be equally representative for all. This review does not also give account to quality of health care at the national level, which may not necessarily be influenced by number of health professionals and available facilities.

In conclusion, the physicians and hospitals to population ratios were extremely lower than the majority of African countries. Beyond the number, the available hospitals were not well equipped in terms of treating some of the common causes of maternal and perinatal mortality. The cumulative 
effect has probably contributed to the high maternal and perinatal mortality in the last three decades in Ethiopia.

The government of Ethiopia needs to give due emphasis to increase the number of physicians and hospitals to meet the maternal health service need of the alarmingly increasing population. Availing essential services in a large scale (like blood transfusion, neonatal resuscitation and magnesium sulphate) should be given special emphasis.

\section{ACKNOWLEDGEMENT}

We would like to thank PANE and KMG Ethiopia for the modest financial granted for this review. We are also grateful to UNFPA Ethiopia for their generous financial support to cover the publication fee.

\section{REFERENCES}

1. Prata N, Passano P, Sreenivas A, Gerdts CE. Maternal mortality in developing countries: challenges in scaling-up priority interventions. Women's Health 2010; 6(2), 311-327

2. Baru RV. Socio-economic inequalities in access to maternal health care in India: Challenges for policy. www.who.int/global_health_histories/seminar

3. Alvarez JL, Gil R, Hernández V, Gil A. Factors associated with maternal mortality in Sub-Saharan Africa: an ecological study. BMC Public Health 2009; 9:462. doi:10.1186/1471-2458-9-462

4. Sharma G. Maternal, perinatal and neonatal mortality in South-East Asia region. Asian Journal of Epidemiology 2012; 5(1): 1-14.

5. Bhutta ZA, Darmstadt GL, Haws RA, Yakoob MY, Lawn JE. Delivering interventions to reduce the global burden of stillbirths: improving service supply and community demand. BMC Pregnancy Childbirth 2009; 9(Suppl 1):S7. doi:10.1186/1471-2393-9-S1S7.

6. Titaley CR, Hunter CL, Dibley MJ, Heywood P. Why do some women still prefer traditional birth attendants and home delivery? A qualitative study on delivery care services in West Java Province, Indonesia. BMC Pregnancy Childbirth 2010; 10:43. http://www.biomedcentral.com/14712393/10/43

7. Berhan Y, Berhan A. Maternal mortality in Ethiopia: 30 years story. Ethiop J Health Sci 2014; Special issue 1.

8. Berhan Y, Berhan A. Perinatal mortality trend in Ethiopia. Ethiop J Health Sci 2014; Special issue 1.

9. The 1984 transitional Government of Ethiopia Office of the population and housing census. Analytical Report at National Level, 1991.

10. Central Statistics Agency. The 1994 Federal Government of Ethiopia Office of the population and housing census. Analytical Report at National Level, 1999.

11. Central Statistics Agency. The 2007 Federal Government of Ethiopia Office of the population and housing census commission. Analytical Report at National Level, 2008.

12. Berhan Y. Medical doctors in Ethiopia: production, attrition and retention. Ethiop Med $J$ 2008; 46 (Supp 1): 1-75.

13. Federal Democratic Republic of Ethiopia. Ministry of Health Health and Health Related Indicators 2010/2011). Policy planning directorate. www.moh.gov.et

14. World health organization. World Health Statistics 2013. Last accessed in August 2013: www.who.int/entity/gho/.../world_health_stati stics/EN_WHS2013_Full.pdf.

15. Gerein N, Green A, Pearson S. The implications of shortages of health professionals for maternal health in subsaharan Africa. Reprod Health Matters 2006;14(27):40-50.

16. World Health Organization. WHO Global Atlas of the Health Workforce. apps.who.int/globalatlas/docs/HRH

17. Rogo KO, Oucho J, Mwalali P. Disease and Mortality in Sub-Saharan Africa. www.ncbi.nlm.nih.gov/books/.

18. Gaym A. Maternal mortality studies in Ethiopia-magnitude, causes and trends. Ethiop Med J 2009; 47(2): 95-108.

19. Yaya Y, Lindtjørn B. High maternal mortality in rural south-west Ethiopia: estimate by using the sisterhood method BMC Pregnancy Childbirth 2012; 12:136 http://www.biomedcentral.com/14712393/12/136 
20. Oti SO, Odimegwu C. Perinatal Mortality in Nigeria: Do Place of Delivery and Delivery Assistants Matter? TODEMOJ 2011; 4: 1-10.

21. Berhan Y, Berhan A. Causes of maternal mortality in Ethiopia: A significant decline in abortion related mortality. Ethiop J Health Sci 2014; Special issue 1.

22. Rosenberg T, Pariente G, Sergienko R, Wiznitzer A, Sheiner E. Critical analysis of risk factors and outcome of placenta previa. Arch Gynecol Obstet 2011; 284(1): 47-51.

23. Crane JM, van de Hof MC, Dodds L, Armson BA, Liston R. Maternal complications with placenta previa. Am J Perinatol 2000; 17: 101-105.

24. Yifru Berhan. Predictors of Perinatal Mortality in Women with Placenta Previa and Placental Abruption: Experience from low income country. $J$ Pregnancy 2014. http://www.hindawi.com/journals/jp/2014/307 043/

25. Khan KS, Wojdyla D, Say L, Gülmezoglu AM, Van Look PFA. WHO analysis of causes of maternal death: a systematic review. Lancet 2006; 367: 1066-74

26. Bates I, Chapotera G, McKew S, van den Broek N. Maternal mortality in sub-Saharan Africa: the contribution of ineffective blood transfusion services. BJOG 2008; 115:13311339.

27. The Ethiopian Red Cross Society. National Blood Bank Service. Last retrieved July 2014 from:

http://www.redcrosseth.org/cp_health_care_bl ood_bank.php.

28. Duley L, Gulmezoglu AM, Henderson-Smart DJ. Magnesium sulphate and other anticonvulsants for women with pre-eclampsia (Cochrane Review). Oxford: The WHO Reproductive Health Library CD-ROM No. 10; 2007.

29. Altman D, Carroli G, Duley L, Farrell B, Moodley J, Neilson J, et al. Do women with preeclampsia and their babies, benefit from magnesium sulphate? The Magpie trial: a randomised and placebo-controlled trial. Lancet 2002; 359:1877-90.

30. Tukur J. The use of magnesium sulphate for the treatment of severe preeclampsia and eclampsia. Ann Afri Med 2009; 8: 76-80.
31. Sisay D. Ethiopia: UNICEF and WHO join forces to save children. Africa research library 2009.http://www.afriknews.com/article16262.html 